\title{
La violencia y lo abyecto \\ en Bajo este sol tremendo (2009) de Carlos Busqued y El otro hermano (2017) de Israel Adrián Caetano ${ }^{1}$
}

\author{
Violence and the abject \\ in Bajo este sol tremendo (2009) of Carlos Busqued \\ and El otro hermano (2017) of Israel Adrián Caetano
}

\author{
SABINE SCHLICKERS \\ Universität Bremen \\ Sabine.Schlickers@uni-bremen.de \\ ORCID ID: 0000-0001-8645-9119
}

\begin{abstract}
Resumen: Israel Adrián Caetano adaptó con El otro hermano (2017) congenialmente la novela Bajo este sol tremendo de Carlos Busqued (2009) en la que el pasado de la dictadura se vincula con el presente narrativo a través de la violencia de un exmilitar de la fuerza aérea. Duarte es un tipo sórdido, horrible y a la vez extrañamente atrayente, por lo que se correlaciona con la noción de lo abyecto de Kristeva (1982). Su representación se distingue de la de los militares de la dictadura en el «cine de desaparecidos», como se demuestra con un breve análisis de Garage Olimpo (1999). La ambigüedad de la violencia representada en El otro hermano provoca los mismos efectos de atracción y rechazo en el espectador implícito y lo llevan a una reflexión mediática y genérica.
\end{abstract}

Palabras clave: adaptación filmica, violencia sistémica y subjetiva, lo abyecto, cine de desaparecidos, posdictadura, Carlos Busqued, Adrián Caetano.

\begin{abstract}
Israel Adrián Caetano's El otro hermano (2017) is a congenial adaptation of Carlos Busqued's novel Bajo este sol tremendo (2009), in which the past of the dictatorship is linked to the narrative present through the violence of an exmilitary member of the air force. Duarte is a sordid, horrible and at the same time strangely appealing type, thus correlating with Kristeva's (1982) notion of the abject. His representation is distinguished from that of the dictatorship's military in the «cinema of the disappeared», as a brief analysis of Garage Olimpo (1999) demonstrates. The ambiguity of the violence depicted in El otro hermano provokes the same effects of attraction and rejection in the implicit viewer and leads to a mediatic and generic reflection.
\end{abstract}

Keywords: Film Adaptation, systemic and subjective violence, the abject, cinema of the disappeared, postdictatorship, Carlos Busqued, Adrián Caetano.

\footnotetext{
${ }^{1}$ Durante el proceso de edición de este trabajo, recibimos la noticia del fallecimiento de Carlos Busqued el 29 de marzo de 2021. La autora dedica este artículo a su memoria.
} 
El otro hermano (2017), de Israel Adrián Caetano, es una adaptación cinematográfica de la novela Bajo este sol tremendo (2009), la primera novela de Carlos Busqued. Nacido en 1970 en el Chaco, Busqued reside actualmente en Buenos Aires, donde publicó asimismo su segunda novela, también en Anagrama (Magnetizado, 2018). Según la presentación en la contratapa de Bajo este sol tremendo, se trata de

una novela poderosa, sin reflexiones psicológicas ni demasiados datos concretos del porqué de la anestesia emocional de sus protagonistas. [...] Está construida desde el relato de las acciones de estos outsiders casi absolutos, sin guiños generacionales ni discursos éticos o políticos sobre la tortura, el crimen, la culpa, el vacío existencial o la historia reciente del país. $\mathrm{Y}$, sin embargo, estos temas asoman en la trama $[\ldots]$.

En adelante trato de mostrar que «estos temas»-presentados por un narrador heterodiegético tan impasible como sus personajes- se relacionan en la película de Caetano con el pasado de la dictadura y que asoman a través de la violencia representada por el protagonista Duarte (fot. 1).

Este ex militar de la fuerza aérea (interpretado genialmente por Leonardo Sbaraglia) es un villano sórdido, pero también seductor, simpático - en argentino se diría que es un chanta, expresión del lunfardo para referirse a un descarado, desvergonzado, un insolvente moral- $-^{2}$. Su mayor pasión es la guita, y hace de todo para conseguirla, por lo que no es una persona fiable. Organiza, por ejemplo, un seguro de vida fingido para que Javier cobre dinero después del cruel asesinato de su madre y de su hermano, pero él cobra la mitad como coima. O, en otra ocasión, se entera a través de «un dato» comprado que cierta mujer tiene mucho dinero en el banco y la secuestra. Estas escenas demuestran que la corrupción forma parte de la violencia sistémica que el cine cuestiona, al igual que otros géneros y medios como, por ejemplo, la novela criminal -pero no es tarea del arte encontrar una solución a la misma-.

A la hora de darle el dinero del seguro trucho a Javier, Duarte le dice que tuvo que pagar más de lo previsto a la gente que había sobornado, pero el espectador implícito duda que miente.

La mayor fuente de ingresos de Duarte proviene de secuestros. Para gestionarlos, tiene un ayudante, un joven llamado Daniel, que

\footnotetext{
${ }^{2}$ En la novela es más viejo y obeso y carece de la atracción ambigua del personaje de Caetano.
} 
La violencia y lo abyecto en Bajo este sol tremendo de Carlos Busqued...

fuma constantemente porros mientras mira documentales de animales ${ }^{3}$.

Daniel esconde a los secuestrados en el sótano de su casa -esta desaparición de civiles en la postdictadura vincula la película implícitamente con el «Proceso de Reorganización Nacional» e intertextualmente con la película El Clan (2015), de Pablo Trapero-.

A lo largo de El otro hermano se hace evidente la conexión entre los personajes: Javier llega desde Buenos Aires en su auto destartalado a un pueblo ubicado cerca de Resistencia, capital de la provincia del Chaco, porque había recibido una llamada de Duarte para avisarle que su madre y su hermano habían sido asesinados por el amante de la madre, y que posteriormente este mismo se había suicidado. El motivo no se aclara. Así, por lo menos, reza la versión de los hechos de Duarte a la que vuelvo más adelante. El asesino-suicida había sido compañero militar de Duarte y era el padre de Daniel. Por consiguiente, la madre de Daniel -interpretada por Ángela Molina- es la exmujer de este asesino. Pero el título El otro hermano -no muy acertado ni atractivono se refiere a Javier, el hermano del muerto, sino a otro hermano de Daniel que había muerto pocos meses después de haber nacido y que se llamaba igual que él.

En fot. 2 se ve a Daniel y a su madre desde el punto de vista del hermanito muerto en su tumba. Esta perspectiva «imposible» remite a Pulp Fiction (1994), donde el extremo ángulo contrapicado se encuentra en una escena en la cual los criminales están focalizados desde el punto de vista de unas armas que se guardan en el baúl del coche.

A pesar de que Duarte es un tipo sórdido, a la vez, es extrañamente atrayente. De ahí que me parezca interesante correlacionarlo con la noción de lo abyecto de Kristeva (1982). Lo abyecto no es lo grotesco, sino lo que reside en cierta transgresión del orden: «It is thus not lack of cleanliness or health that causes abjection but what disturbs identity, system, order. What does not respect borders, positions, rules» (Kristeva, 1982: 4). Lo abyecto está en el borderline, por ello fascina y horroriza a la vez. Mutatis mutandis, esta mezcla contradictoria entre lo fascinante y lo tremendo caracteriza asimismo la ambigüedad de la violencia representada en las imágenes fílmicas, que provocan los mismos efectos de atracción y rechazo en el espectador implícito.

\footnotetext{
${ }^{3}$ En la novela Daniel se retrata solo hacia el final (Busqued, 2009: 159), cuando coincide con Javier: es mayor y grandote, lo que no impide que Duarte lo apode «Danielito». Además, se hace repetidas veces pis en la cama.
} 
Para obtener estos efectos, Duarte necesita un antagonista, y lo encuentra en Javier, un hombre común e indolente que, al no haber tenido nunca contacto ni con su madre ni con su hermano, se queda sorprendido cuando Duarte le cuenta que había obtenido su número de teléfono a través de su madre.

Javier vive en Buenos Aires y ha perdido su empleo en una oficina pública simplemente porque no ha ido a la misma durante un año entero. Con ello se puede decir que está excluido voluntariamente del sistema social, es decir, lo contrario de lo que suele tratar el cine argentino, para el que normalmente la exclusión social se presenta como «producida $[\ldots]$ por un nivel extraordinario de disciplina y control, formas latentes de una violencia sistémica» (Kantaris, 2005: 40).

Javier se deja llevar mansamente por Duarte a una casa chata que sirve como morgue. Allí Duarte le pasa un cubo antes de mostrarle los cadáveres para identificarlos - escena grotesca porque los rostros están completamente destrozados-. Javier necesita el cubo para vomitar, pero fuera de eso se muestra impasible: más tarde tira incluso la ceniza de las urnas al retrete de la casa de su hermano, en la cual se instala. Su hermano padecía del síndrome de acumulación compulsiva. Sin embargo, Javier se vuelve lentamente activo y tira toda la basura para luego venderla a un chatarrero.

Bajo el influjo de Duarte, Javier se convierte paulatinamente «en un delincuente, casi sin darse cuenta y sin hacer casi nada», como advierte Caetano en una entrevista ${ }^{4}$ : primero acepta el fraude con el seguro, luego recibe una llamada de Duarte pidiéndole hospedaje para sí mismo y una «tía enferma», que resulta ser una mujer mayor secuestrada. Duarte le ofrece 5 lucas, o sea 5000 pesos (que serían 225 euros), pero Javier dice que no quiere meterse en un quilombo. Cuando Duarte redobla la suma, acepta sin más. Después Duarte le pide acompañar a la «tía con Alzheimer» -la habían dopado y puesto en una silla de ruedas-al banco, ofreciéndole 25.000 pesos, más de mil euros. Javier saca allí 300.000 pesos - el dato que Duarte había comprado era bueno-.

Duarte ejerce la violencia de manera sádica: golpea, viola y sodomiza brutalmente a sus víctimas secuestradas. La violación es un ejercicio de poder, uno redoblado porque las víctimas de Duarte están

\footnotetext{
${ }^{4}$ https://www.youtube.com/watch?v=o6aWxmJaySs [28.10.2020]. Aquí Caetano añade algunas escenas, aumentando las actividades criminales de Javier que se queda en la novela indolentemente en casa de su hermano, fumando porros día y noche y mirando la televisión.
} 
La violencia y lo abyecto en Bajo este sol tremendo de Carlos Busqued...

atadas y no pueden defenderse. En el primer caso se trata de un chico (00:21: 15-23), y en esta ocasión la violación no se muestra, pero se insinúa claramente por el pánico del chico cuando Duarte se abre la hebilla del cinturón -con lo cual queda claro que no es la primera vez que Duarte abusa de este chico, más vulnerable todavía por tener el síndrome Down ${ }^{5}$.

En el segundo caso -la iteración hace otra vez suponer que hubo más casos- se trata de una mujer mayor secuestrada (1:17:271:18:15). El hecho de que los secuestradores no le venden los ojos es mala señal, porque esto indica que la van a matar. La violencia corporal, sexual, verbal y emocional de Duarte ${ }^{6}$ corresponde a los efectos que produce en el receptor, quien se siente afectado emocional, cognitiva e incluso fisiológicamente.

Concluyo que, con esta puesta en escena de la violencia subjetiva, individual de Duarte, este filme contradice la teoría vigente (Kantaris, 2005), según la cual el cine latinoamericano de violencia cuestiona la violencia sistémica (lo que demuestro más adelante con algunos ejemplos del «cine de desaparecidos»).

Uno no se puede fiar de un chanta sádico como el exsuboficial Duarte. La madre de Daniel le cuenta antes de suicidarse con raticida que su marido se había vuelto malo debido a la nefasta influencia de Duarte. El suicidio de la madre es un acto desesperado para salvar a Daniel y no sirve, obviamente, para nada -porque Daniel ya está en manos de Duarte, y ella lo sabe perfectamente-. La madre es otra

\footnotetext{
${ }^{5}$ De modo parecido, el autor implícito Busqued insinúa tan solo la violencia a través de los gritos del chico con «la horrible cara [...], pegada desprolijamente a una cabeza dos números más grande», que se calma con unos dibujos japoneses en el canal televisivo. Cuando llega Duarte, empero, grita nuevamente, lo que se transmite a través de la auricularización interna de Daniel, que escucha después de que la puerta del sótano se haya cerrado: «Primero sonaban agudos, como un cerdo asustado. Después se apagaron un poco, como si al cerdo le hubieran envuelto la cabeza en una toalla» (Busqued, 2009: 34 y ss.).

${ }^{6}$ El autor implícito Busqued trabaja con vacíos, delegando los actos de violación y de violencia a la fantasía del lector. Al igual que en el caso del chico con sindróme Down, Daniel no asiste a los actos de tortura, sino que registra solo las huellas que dejaron en el cuerpo: «Cuando Danielito bajó a llevar la cena (hamburguesas con puré), el aire estancado estaba espeso y con olor a una mezcla de porro, esperma y jabón, rastros de la visita de Duarte a la señora [secuestrada]. Duarte la había limpiado, pero eran evidentes los golpes y pequeños tajos en la boca y arcos superciliares. En el resto del cuerpo también la había castigado y algunas partes estaban empezando a hincharse» (Busqued, 2009: 130).
} 
víctima de Duarte, ni siquiera puede imponerse sobre los perros de Daniel, razón por la cual uno la muerde fuertemente.

La violencia de y contra animales resulta ser otro tema recurrente, tanto en la novela como en la película; llamativa es, por ejemplo, la escena en la cual Duarte pisa a un escarabajo enorme (fots. 3 y 4 ).

No sorprende a nadie que Duarte quiera matar a Javier y a la secuestrada cuando tiene los 300.000 pesos en el bolsillo. Sin embargo, Javier parece no darse cuenta de nada, ya que sube ingenuamente otra vez a la camioneta para que Duarte lo lleve a la estación. Pero Daniel y Duarte lo conducen junto con la mujer a un terreno abandonado donde estalla un tiroteo absurdo del cual sale como único sobreviviente Javier.

Las referencias al género del western destacan no solo por el duelo con armas de fuego, sino asimismo por la desaceleración atormentadora del ritmo narrativo. Pero destacan también diferencias: en la película de Caetano, el duelo no corresponde a un asunto de honor ni los contrayentes se miden largamente parados con la mirada fija esperando a ver quién saca primero el arma. Además llama la atención que los tres hombres tiren con la mano izquierda, mientras que en el western clásico el arma aparece en la mano derecha, a no ser que los cowboys tiren con ambas manos a la vez ${ }^{7}$.

En El otro hermano la sangre brota de las heridas que se muestran en primeros planos con todo lujo de detalle. Los golpes fuertes de Duarte en la cara de Javier producen un eco extraño en el off. Todos estos recursos fílmicos producen cierta estetización abyecta que lleva a una reflexión mediática y genérica del espectador implícito. La puesta en escena extrañante e hiperbólica de la violencia hace recordar las películas de Tarantino y también su reminiscencia a Relatos salvajes, filme en el cual Leonardo Sbaraglia actúa (en el segundo episodio de los coches).

En la película de Caetano, en cambio, la exageración no produce ni comicidad ni distancia. Tan solo al final Daniel y Javier demuestran reacciones emocionales: Daniel no logra matar a Javier; él, que ha mantenido escondidos los ojos a lo largo de la película bajo una visera, ahora, en su agonía, mira directamente a los ojos de Javier. Este le presiona la herida mortal y le pide perdón por retirar la mano y dejarlo morir (fot. 5). Javier, el tipo inofensivo que se deja convertir en

\footnotetext{
${ }^{7}$ El final de la novela carece de este showdown irónico, termina sobriamente con un accidente nocturno en la ruta en el cual el conductor, Daniel, ha fumado tanto que no puede reaccionar a tiempo cuando aparece una vaca en la ruta. El único sobreviviente es Javier, quien se apodera del dinero y se va.
} 
La violencia y lo abyecto en Bajo este sol tremendo de Carlos Busqued...

delincuente y que confía hasta el último minuto en Duarte, no solo lo remata sino que sigue disparándole muchas veces seguidas aunque Duarte ya está muerto. Después de este ataque de violencia, que le sirve tal vez para recuperarse de su propio miedo de morir experimentado pocos minutos antes, saca tranquilamente el dinero del coche y se marcha, posiblemente a Brasil, como planeaba, para comenzar una vida nueva. Además no puede quedarse en Argentina: las cámaras en el banco lo han grabado junto con la secuestrada, que ahora también yace muerta en el suelo.

La película tiene, entonces, una estructura circular: al principio, Javier llegó al pueblo de provincia y se topó con la sangre de la masacre de tres personas disparadas, ahora es él el que se marcha dejando a tres cadáveres disparados. No obstante, diría que la estructura no es cerrada, porque queda abierto si Duarte le había contado la versión correcta de los hechos o si él mismo es el responsable de la muerte de la madre, del hermano y del amante de la madre de Javier. Me inclino a creerlo, porque así se resolvería el dato extraño de que Duarte tuviese el contacto de Javier que la madre de Javier probablemente no tenía. Y lo primero que hizo Duarte fue proponerle el fraude con el seguro de vida, recurso que quiere repetir, por cierto, con la madre muerta de Daniel. También supongo que engañó a Javier sacándole una provisión demasiado alta como "propina" para sus compinches en el seguro o en el Estado.

Resulta obvio que el malvado ex militar Duarte es un carácter fascinante, lo que expliqué con la noción de lo abyecto. La interpretación de este carácter es una concretización genial de Caetano, porque el Duarte de Busqued no es ni fascinante ni atrayente. En una página gallega sobre cine europeo (lo que es algo raro porque se trata de una película latinoamericana), Nunes (2017) critica, no obstante: «El Otro Hermano acerta no tratamento da violência mas nom na exploraçom psicológica dos seus personagens. Ficará na memória do público de Cineuropa como uma peça de cinema bestial». Parece persistir cierta «mirada tercermundista» que considera a los latinoamericanos como bárbaros. Espero haber podido demostrar que la película es mucho más sutil y compleja al presentar a un exmilitar que atrae y repugna a la vez, a otro protagonista indolente que se convierte en delincuente sin hacer casi nada y al poner en escena de un modo particular la violencia que lleva tanto a la inmersión e identificación como a la distancia reflexiva del espectador implícito.

Duarte remite a la degradación moral de los militares de la dictadura argentina, y en este sentido la violencia subjetiva representada por él cumple una función alegórica. Pero esta no se 
vuelve tan transparente y didáctica como en el así llamado «cine de desaparecidos» argentino, donde predomina, en cambio, la violencia sistémica (ver supra) y una consiguiente representación estereotipada de guerrilleros guapos y militares malvados ${ }^{8}$. Para comprobarlo, analizo en adelante brevemente una película de este cine que destaca por concentrar su trama en un campo de concentración. Porque tan solo la posterior Crónica de una fuga (2006), también de Caetano, como la anterior La noche de los lápices (1986), de Héctor Olivera, situaron su trama en estos campos, de los cuales no había habido registro audiovisual:

Las imágenes que conocemos son a posteriori, a partir de la Conadep (Comisión Nacional sobre la Desaparición de Personas) por ejemplo, siendo en su gran mayoría ruinas o instalaciones desmanteladas. La otra fuente proviene de las películas: el cine fue la que moldeó el imaginario del pasado dictatorial (Zylberman, 2013).

Garage Olimpo (1999), de Marco Bechis, muestra el trabajo cotidiano dentro de un centro de detención: los torturadores son jóvenes, con aspectos físicos normales. Ejercen su trabajo metódicamente, aunque a veces se sobrepasan con la picana, calculando mal la dosis, como sucede con la protagonista en su primera sesión (21:00). Sucede que cometen errores de negligencia, como no percatarse en la revisión de un recién llegado que llevaba escondida una pastilla de cianuro para suicidarse (24:00). Tienen horarios, fichan al entrar y se turnan. Regularmente el jefe los cita en su oficina para hablar sobre los resultados; siempre se le ve con listas en la mano en las que apunta meticulosamente las entradas y salidas de los detenidos.

A uno de los patotas, Félix, le toca el segundo turno -idespués de diez horas de tortura sin pausa!-, con una «maestrita de pobres» de la que no se llega a saber ningún «otro delito» a lo largo de la película, es decir, ni siquiera es una montonera o guerrillera del ERP. Se llama María, es una chica linda de 18 años que convive con Félix en la pensión de su madre. Félix está enamorado de ella, pero ella no le da bola.

\footnotetext{
${ }^{8}$ «El cine de ficción carece [del] nivel metaficcional [de las novelas sobre la dictadura] y juega más con los afectos y emociones de los espectadores, recurriendo a ciertas estructuras melodramáticas ubicadas en el ámbito familiar. Los guerrilleros son siempre guapos, simpáticos y admirables mártires de la causa que queda, no obstante, por lo común muy poca clara -en Cordero de Dios no se llega a saber ni siquiera si la pareja simpatiza solamente con los guerrilleros o si forman parte activa de ellos-, o bien son víctimas guapas e inocentes, como en Crónica de una fuga [y Garage olimpo]» (Schlickers, 2010: s. pág.).
} 
La violencia y lo abyecto en Bajo este sol tremendo de Carlos Busqued...

Acostada y desnuda, apenas recuperada la conciencia, María reconoce en seguida a Félix, sin entender qué hace en este lugar, y él la tranquiliza diciéndole que no le habían hecho nada, que estaba allí en un control. Esta escena tierna y esperanzadora se interrumpe abruptamente con la entrada del jefe de Félix, quien le da quince minutos para hacerla hablar y lo manda a venir después a su oficina. Félix saca rápidamente la picana y le insiste a María en hablar. Pero la hipótesis del espectador implícito de que Félix actúe así porque la obediencia puede más que el amor se resquebraja en el siguiente plano, que muestra que las celdas de tortura se vigilan continuamente con cámaras.

Félix vive bajo la identidad falsa de ser mecánico, lo que corresponde irónicamente al hecho de que su lugar de trabajo sea un garaje en pleno centro de Buenos Aires, que lleve allí siempre un maletín de acero (con la picana dentro) y que actúe de modo mecánico. Hace todo pausada y tranquilamente - comer, andar, moverse- y habla quedo con sus víctimas, a quienes saca, no obstante, impasiblemente la ropa cuando ya no les sirve más.

En los recreos, los torturadores juegan al ping-pong, llaman a sus esposas, hojean revistas. En contraposición, en las sesiones de tortura ponen música alegre, muy alta, para que no se escuchen los gritos de dolor en la calle. Pero los torturadores no parecen tener la inclinación sádica de Duarte, sino que actúan guiados por su tarea de arrancarles datos a los «subversivos». Al lado de Félix destaca tan solo el Turco, que se parece a Duarte por el afán de querer enriquecerse. Por ello arma inteligentemente toda una historia cuando se entera de que la madre de María es la propietaria única de una grand casa. Con la promesa de sacar a su hija, ella lo acompaña a un notario para que él le compre la casa en efectivo; luego, la conduce a las afueras donde le pega un tiro y se lleva el sobre con el dinero (1:04). Este episodio se parece, de hecho, al último secuestro en El otro hermano, en el cual Duarte hace llevar a la mujer dopada en silla de ruedas al banco.

Pero comparando ahora las dos películas más detenidamente, resulta que Garage Olimpo representa la violencia sistémica, mientras que El otro hermano la violencia subjetiva. La violencia sistémica tiene que ver con la temática de la película de Bechis: Garage Olimpo revela las prácticas de la desaparición de miles de personas y denuncia a los militares responsables de este crimen que caminaban en la época del estreno de la película, en 1999, libremente por la calle, como se 
escribe en el último título de crédito ${ }^{9}$. De ahí se explica que el autor implícito coloque un atentado como acto de justicia poética dentro de la diégesis: el general del Garage Olimpo se convierte en víctima de la amiga de su hija, una joven montonera que se aprovecha del acceso a su casa supervigilada para ponerle una bomba debajo de la cama.

Lo que distingue a Félix de los demás victimarios no es su aspecto -es, como los demás, joven, delgado, ni feo ni hermoso--, sino el hecho de que esté enamorado de su víctima. Su conducta es, empero, ambigua: no se llega a saber si hace todo lo que puede para ayudarla por amor, como sobornar a sus compañeros para que no la golpeen demasiado duro, traerle comida de la calle o incluso salir con ella a dar una vuelta. O si, por otro lado, se aprovecha de la situación para holgarse con quien lo había desdeñado antes, cuando convivían en la pensión de la madre de ella. Tras el intento de escape de María, él le hace una escena de amante traicionado, al que hubiera «querido dejar». Ella se somete a todo porque Félix es su ancla, el único que podría salvarla, pero de hecho Félix la manda involuntariamente a la muerte al salir con ella sin autorización. Esta transgresión de las estrictas normas de conducta que reinan dentro del centro de detención será duramente sancionada, y carcajeada por sus compañeros que están celosos o hartos de las extravagancias caballerescas de Félix, como decorarle cursimente la celda o llevarle flores a María. Cuando Félix vuelve tarde con María al garaje, se está preparando otro «traslado». Ya han subido a casi todos los detenidos a un carro, cuando un compañero le dice a Félix que el general había dado la orden de mandarla a María también. Félix presencia con impotencia cómo le quitan los zapatos y cómo le inyectan una jeringa. Ella sube y lo mira dudando, intuyendo lo que pasa, porque los prisioneros no creen en el cuento del traslado a otro penal. Félix debe marcharse en seguida, porque el general lo cita a su oficina ${ }^{10}$, como al principio, cuando había «entrevistado» por primera vez a María.

\footnotetext{
${ }^{9}$ Bajo el gobierno de Menem (1989-1999) reinaba la impunidad; la ley de amnistía fue cancelada en 2003. «Sólo en el año 2005 se hallaron los primeros cadáveres de los llamados vuelos de la muerte. Esta “práctica" llegó a conocerse en 1995, cuando el periodista Horacio Verbitsky publicó El vuelo, basándose en las confesiones del oficial Adolfo Scilingo. Liliana Heker trató los vuelos un año después en su novela El fin de la historia. En 1997, Scilingo se presentó voluntariamente ante el juez estrella Baltasar Garzón en España porque en Argentina existía la "Ley de Punto Final" que prohibía reabrir el caso» (Schlickers, 2010: s. pág.).

${ }^{10}$ Debe de ser otro general, porque el anterior fue asesinado y su voz es distinta, pero no aparece en la pantalla.
} 
El siguiente plano muestra en ángulo picado un avión moviéndose lentamente en las nubes, acompañado por la canción a la bandera argentina Aurora, una bella ópera al estilo italiano creada en 1908. Esta puesta en escena estetizante del atroz vuelo de la muerte refiere intermedialmente a la escena de Apocalypse Now (1979) en la que los vietnamitas huyen desamparados mientras que se acercan los helicópteros con los norteamericanos armados con armas de tiro rápido y bombas. La crueldad de esta escena se mezcla con el sentimiento ambiguo de lo sublime (Chung, 2016), que se produce por el hecho de que los soldados escuchen en este momento una ópera de Wagner, «La cabalgata de las valkirias», que los anima al tiroteo que sigue. La diferencia con respecto a Garage Olimpo reside en el hecho de que la música sublime se reproduce en la película norteamericana a nivel intradiegético, contrastando fuertemente con la matanza alegre; en el filme argentino, en cambio, la música se reproduce a nivel extradiegético. Así, la sensación de lo sublime queda perversamente relegada al espectador implícito que mira cómo se abre lentamente la escotilla de carga del avión. Debido al típico acto de protención, el espectador implícito se imagina cómo los cuerpos narcotizados de los prisioneros caerán al mar, porque la película ya no muestra lo evidente, la desaparición, que se vuelve aquí horriblemente concreta.

Como se mencionó al principio, en la novela de Carlos Busqued y en la adaptación de Israel Adrían Caetano el pasado de la dictadura asoma solo indirectamente a través de la violencia cruel y arbitraria de Duarte, el exmilitar de la fuerza aérea. El narrador de la novela es absolutamente impasible, pero a la vez es más discreto que la instancia narrativa audiovisual, puesto que insinúa tan solo los actos de violencia. Para ello recorre a la auricularización de Daniel, que escucha impasiblemente los gritos de los secuestrados en el sótano y huele, cuando entra allí, el esperma eyaculado de Duarte. En concordancia con el tono lento de la narración, que menciona todos los porros que los personajes fuman -y fuman varios por día-, y que transcribe largos fragmentos de los documentales sobre animales que Daniel mira cada día por horas, el autor implícito Busqued eligió un final menos dramatizado y espectacular que Caetano. Pero gracias a lo que sigue a su showdown, o mejor dicho shutdown, hay en la película una escena de gran ternura entre Javier y Daniel que tiñe el filme de un aire triste del que la novela carece. 
Sabine Schlickers

\section{IMÁGENES}

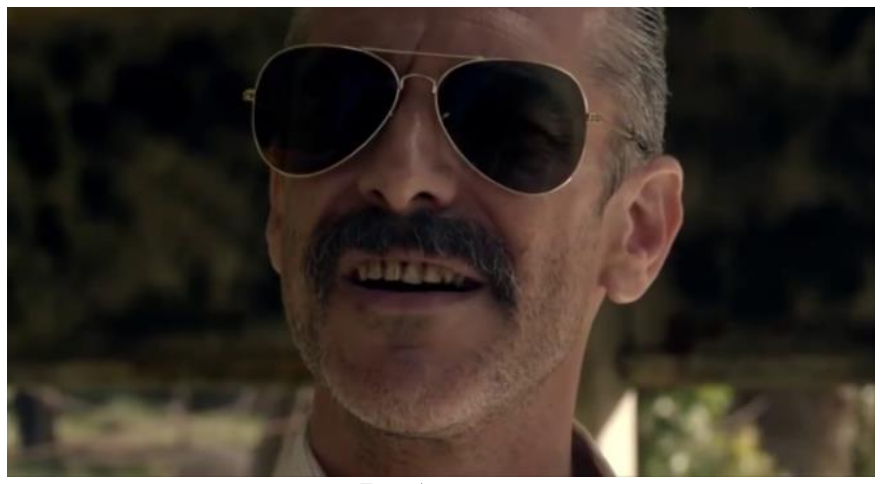

Fot. 1

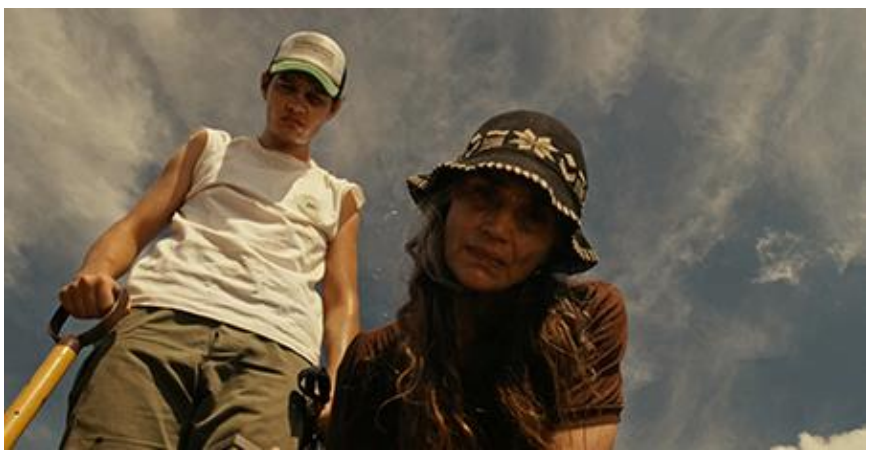

Fot. 2

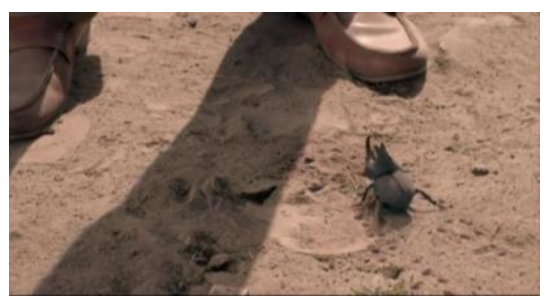


La violencia y lo abyecto en Bajo este sol tremendo de Carlos Busqued...

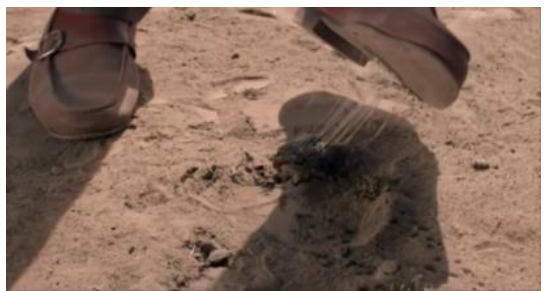

Fots. 3 y 4

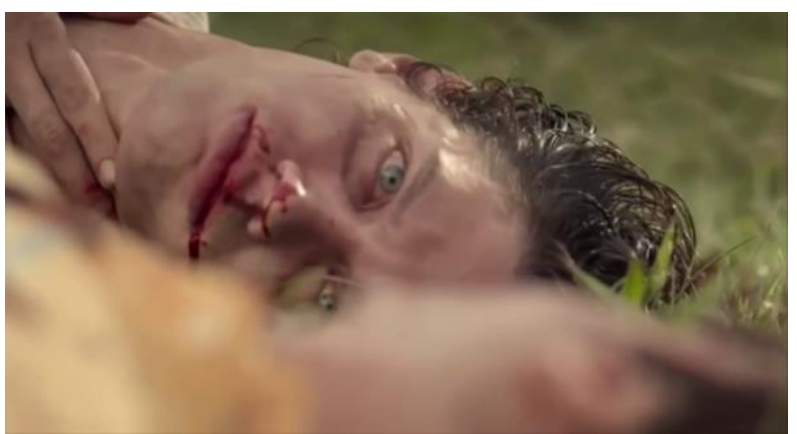

Fot. 5

\section{BibliogRAFÍA CITADA}

BusQued, Carlos (2009), Bajo este sol tremendo, Barcelona, Anagrama. CHung, Jihae (2016), Das Erhabene im Kinofilm: Ästhetik eines gemischten Gefühls, Marburg, Schüren.

KANTARIS, Geoffrey (2005), «Visiones de la violencia en el cine urbano latinoamericano», Cuadernos del Centro de Estudios en Diseño y Comunicación, 18, págs. 39-46.

Kristeva, Julia (1982), Powers of Horror. An Essay on Abjection, New York, Columbia UP.

Nunes (2017), «Crónicas de Cineuropa 2017: El Otro Hermano (Israel Adrián Caetano, 2017)», Mola!, s. pág. [En línea: http: / / mola.gal/cronicas-de-cineuropa-2017-el-otro-

hermano/. Fecha de consulta: 13/12/2019].

SCHLICKERS, Sabine (2010), «La representación literaria y cinematográfica de las dictaduras militares sudamericanas», Amerika: La Mémoire et ses représentations esthétiques en Amérique latine, 
3, s. pág. [En línea: http://amerika.revues.org/1468. Fecha de consulta: 28/10/2020].

ZYLBERMAN, Lior (2013), «Estrategias narrativas de un cine posdictatorial», Revista Afuera, VIII/13, s. pág. [En línea: http: / / www.revistaafuera.com/articulo.php?id $=280 \&$ nro $=13$. Fecha de consulta: 25/08/2020].

Fecha de recepción: 06/11/20.

Fecha de aceptación: 09/02/21. 